\title{
Color and Antioxidant Capacity Preservation of Opuntia spp. Juices by Spray-drying Microencapsulation
}

\author{
Alberto Castañeda-Yañez ${ }^{1}$, Sandra T. Martín-del-Campo ${ }^{1}$, Alejandra San-Martín ${ }^{1}$ \& Anaberta \\ Cardador-Martínez ${ }^{1}$ \\ ${ }^{1}$ Escuela de Ingeniería y Ciencias, Tecnologico de Monterrey Campus Queretaro. Queretaro, Mexico \\ Correspondence: Anaberta Cardador-Martínez, Escuela de Ingeniería y Ciencias, Tecnologico de Monterrey \\ Campus Queretaro. Epigmenio González 500, Fracc. San Pablo, 76130 Queretaro, Mexico. E-mail: \\ mcardador@itesm.mx
}

Received: February 14, $2018 \quad$ Accepted: March 2, $2018 \quad$ Online Published: March 23, 2018

doi:10.5539/jfr.v7n3p16

URL: https://doi.org/10.5539/jfr.v7n3p16

\begin{abstract}
In this work, it was evaluated the effect of microencapsulation using spray drying over natural colorants present in two varieties (red and purple) of prickly pear juice (Opuntia spp.), using three kinds of carrier agents (matrixes). The dried samples after microencapsulation retained a high total amount of the betalains and their antioxidant characteristics. However, some individual betalains were lost after microencapsulation. According to ANOVA results, matrix 3204 showed a more protective effect than matrix 4801 in both microencapsulated juices over color, individual betalains, and antioxidant capacity. Globally, the protective effect was better for purple juices than red juices no matter the matrix used. Principal Component Analysis (PCA) confirmed these results. Matrix 3204 resulted in the best carrier agent since it gave a less disperse PCA group for both color juices. The parameters that separated both PCA matrixes groups were L*, $\mathrm{a}^{*}, \mathrm{~b}^{*}$ and DPPH.
\end{abstract}

Keywords: antioxidant capacity, betalains, prickly pear, Spray-drying Microencapsulation

\section{Introduction}

Opuntia ficus-indica is a cactus originally found in the Gulf of Mexico and the Caribbean. This plant is the cactus with the greatest economic importance of the world due to the use of the cladodes and the fruit named prickly pear (Pimienta-Barrios, Zanudo, Yepez, Pimienta-Barrios, \& Nobel, 2000; Reyes-Agüero, Aguirre-Rivera, \& Hernández, 2005). Prickly pear is an ovoid berry with thorns, which may vary in color, size, and flavor depending on the specific variety of the fruit.

The natural colorants found in the Opuntia genus are betalains which are the red-purple betacyanins and yellow betaxanthins (Butera et al., 2002; Castellar, Obón, Alacid, \& Fernández-López, 2003). Natural pigments are associated with food quality and health benefits and are becoming popular among consumers who increasingly demand them (Castellar, Obón, \& Fernández-López, 2006; Fernandez-López \& Almela, 2001). Colorants added to a product help to maintain food appearance, control color uniformity among batches of different sources, and enhance acceptability (Chattopadhyay, Chatterjee, \& Sen, 2008).

Spray drying is a widely used method to dry and preserve compounds. This procedure is normally chosen because of its economy and suitability compared to other available methods such as freeze-drying (Díaz Sánchez, Santos López, Filardo Kerstupp, Villagómez Ibarra, \& Scheinvar, 2006). Microencapsulation is a packaging technology for liquids or solids forming a micro-particle of a polymeric membrane used to contain a substance of interest; this procedure is performed pursuing the protection of substances from being in contact with the external medium (Parra Huertas, 2010; Yañez et al., 2002).

The main purpose of this job was to determine the efficiency of the microencapsulation process with three kinds of matrices of two Opuntia prickly pear juices over color, betalain content and antioxidant capacity.

\section{Materials and Methods}

\subsection{Sample Preparation}

For this study, red and purple varieties of prickly pear fruit (Opuntia sp.) were selected. For each variety, one batch of $18 \mathrm{~kg}$ box was purchased at a local market in June 2013 at Querétaro, Mexico. Fruits were transported 
to the laboratory and stored at room temperature until processing in a period not longer than $48 \mathrm{~h}$.

Red Fresh (RDF) and Purple Fresh (PRF) prickly pear juices were prepared using the whole batch of fruits to avoid fruit to fruit variations obtaining a uniform batch for each color. Fruits were peeled manually, and the pulp was homogenized in a household blender for $40 \mathrm{~s}$ and seeds were separated. Juices were kept at $4{ }^{\circ} \mathrm{C}$, and the procedure was repeated as many times as necessary to homogenize the whole fruit batch. Then, the pulp was eliminated by centrifugation at $9100 \mathrm{x}$ g at $4{ }^{\circ} \mathrm{C}$ for $20 \mathrm{~min}$ (Hermle Z $383 \mathrm{~K}$, Wehgen, Germany). Supernatants were recovered, and mucilage was eliminated by precipitation with ethanol $96 \%$ Alc.Vol. (Karal León, Gto., México) adding one volume of ethanol to five volumes of prickly pear juice, let solids flocculate, and manually removed them. Obtained juices were labeled RDF and PRF. The total solid content was determined by triplicate using an Abbé refractometer NAR-1T LIQUID (Atago Co., LTD, Minato-ku, Tokyo, Japan) at $20{ }^{\circ} \mathrm{C}$ and reported as ${ }^{\circ} \mathrm{Brix}\left({ }^{\circ} \mathrm{Bx}\right)$.

Next, red and purple concentrated juices (RDC and PRC, respectively) were prepared as follows; RDF and PRF juices were concentrated in a rotary evaporator (Büchi R-215, Flawil, Switzerland) until solids reach a value of $55{ }^{\circ} \mathrm{Bx}$. RDC and PRC samples were kept at $-20{ }^{\circ} \mathrm{C}$ in dark tight closed flasks until analysis and microencapsulation.

\subsection{Microencapsulation Experimental Design}

Three maltodextrins (Maprigel $\AA^{0019}$, Maprigel ${ }^{\circledR} 3204$ and Maprigel ${ }^{\circledR}$ 4801) were evaluated as carrier agents (matrix). These maltodextrins were kindly donated by Materias Primas para la Industria Alimentaria S.A. (San Juan del Río, Querétaro, México).

Microencapsulation of concentrated juices (RDC and PRC) was carried in a Mini Spray Dryer (Büchi Mini Spray Dryer B-290, Flawil, Switzerland).

For each prickly pear color and matrix, a $2^{\mathrm{k}}$ factorial design was carried out. Evaluated factors were injection speed $(2.24$ and $3.36 \mathrm{~mL} / \mathrm{min})$, matrix proportion (19.60 and $26.80 \%)$, and drying temperature $\left(120\right.$ and $\left.140{ }^{\circ} \mathrm{C}\right)$, giving a total of 6 factorial designs. Air blowing was set at $40 \mathrm{~L} / \mathrm{min}$. Each factorial design was carried out in duplicate.

Feed mixtures were prepared by combining the concentrated juices with the carrier agent and cornstarch. Of the total solids in suspension, $20 \%$ came from concentrated juices $\left(55^{\circ} \mathrm{Bx}\right)$, maltodextrins were added according to the factorial design, and starch was added to achieve $100 \%$ of total solids. Finally, water was added to adjust up to $10 \%$ solids final suspension.

\subsection{Betalains Quantification by Spectrophotometry in Prickly Pear Juices}

The Stintzing et al. (2005) method was used to quantify betalains in the fresh and concentrated juice samples. The absorbance of samples was read at $\lambda_{\max }=538 \mathrm{~nm}$ for betanin, and $\lambda_{\max }=480 \mathrm{~nm}$ for indicaxanthin using a spectrophotometer (Labomed, Inc. Spectro UV-VIS Double Beam UVD-3500, U.S.A.). Betacyanins and betaxanthins contents were expressed as betanin or indicaxanthin equivalent $/ \mathrm{mL}$ of juice, respectively. Measurements were done in triplicate.

\subsection{Physicochemical Characterization of Microencapsulated Juices}

The water activity of the samples was measured using an Aqualab (Decagon Devices Aqualab 4TE, U.S.A.), humidity was measured in a Thermoscale (Ohaus MB25 Thermoscale, China) at $125{ }^{\circ} \mathrm{C}$. The color was measured using a Minolta CM-5 spectrophotometer (Konica Minolta) standardized with both black and white standards on transmittance mode, using a Cell CM-A98 $(10 \mathrm{~mm})$, at $20^{\circ} \mathrm{C}$. The color was reported as Hunter $\mathrm{L}^{*}$, $a^{*}, b^{*}$ tristimulus values. The $\mathrm{L}^{*} \mathrm{a}^{*} \mathrm{~b}^{*}$ color space (Commission Internationale de l'Eclairage) is an instrumental measure that correlates numerical values of color with human visual perception. Where $\mathrm{L}^{*}$ evaluates brightness, $a^{*}$ is the red/green coordinates ( $a+$ signals red, a- signals green), and $b^{*}$ the yellow/blue coordinates ( $b+$ signals yellow, b- signals blue). All measurements were done in triplicate.

\subsection{DPPH Antioxidant Capacity in Fresh, Concentrated and Microencapsulated Juices}

Antioxidant capacity was measured in fresh and concentrated and microencapsulated juices. To measure antioxidant capacity in microencapsulated juices, $1 \mathrm{~g}$ of microcapsules were suspended in $10 \mathrm{~mL}$ of water, agitated $30 \mathrm{~s}$ in a vortex, and centrifuged $\left(9100 \mathrm{x} \mathrm{g}, 4{ }^{\circ} \mathrm{C}, 10 \mathrm{~min}\right)$. Supernatants were recovered and kept in the dark at $-20{ }^{\circ} \mathrm{C}$ until analysis. Before analysis, fresh and concentrated juices were water diluted $(1: 4 \mathrm{v} / \mathrm{v})$. Twenty $\mu \mathrm{L}$ of each sample was mixed with $0.2 \mathrm{~mL}$ DPPH $125 \mu \mathrm{M}$ in $80 \%$ methanol (Fukumoto \& Mazza, 2000). Absorbance readings were done after 90 minutes of dark storage incubation at $515 \mathrm{~nm}$ in a Microplate Spectrophotometer (Bio-Rad xMark Microplate Spectrophotometer, Japan). Antioxidant capacity was expressed 
as DPPH discoloration percentage (Burda \& Oleszek, 2001).

\subsection{Betalains Analysis by HPLC in Fresh and Microencapsulated Juices}

To analyze microencapsulated juices, the sample was prepared as described in antioxidant section (2.5). $20 \mu \mathrm{L}$ of samples (fresh, concentrated or microencapsulated juices) were injected to a Zorbax Eclipse XDB-C18 4.6 x 150 $\mathrm{mm}, 5$-micron column in a 1200 series HPLC (Agilent Technologies, California, U.S.A.). The mobile phase was A: 82:12 (v/v) mixture of $\mathrm{KH}_{2} \mathrm{PO}_{4} 0.05 \mathrm{M}$ and methanol, adjusted to $\mathrm{pH} 2.75$ with phosphoric acid; and mobile phase B: methanol. A $1 \mathrm{~mL} / \mathrm{min}$ flux was used in a gradient from 100 to $80 \%$ A during $20 \mathrm{~min}$. The detector was set at $484 \mathrm{~nm}$ and $533 \mathrm{~nm}$ for betaxanthins and betacyanins, respectively. To quantify betalains, calibration curves of Red $40(0-100 \mu \mathrm{g} / \mathrm{mL})$ and Yellow6 $(0-1000 \mu \mathrm{g} / \mathrm{mL})$ were prepared. Values were expressed as equivalent of $\mu \mathrm{g} / \mathrm{mL}$ of Red 40 for betacyanins or Yellow6 for betaxanthins.

\subsection{Statistical Analysis}

Statistical analysis was applied to the microencapsulated samples data sets and was performed using the Statistica software v 13.3 (TIBCO Software, Inc., USA). For all data sets, analysis of variance (ANOVA) was applied to evaluate any significant difference $(\mathrm{p}<0.05)$. The Tukey's HSD (honest significant difference) test was conducted for all the significant factors. Next, Principal Component Analysis (PCA) was carried out to identify the most important parameters in microencapsulation process. PCA made it possible to evaluate the whole data set instead of individual parameters.

\section{Results and Discussion}

\subsection{Betalains Content}

Table 1 shows the total solid and betalains contents of the four types of analyzed juices. Purple prickly pear samples showed higher values of betacyanins and betaxanthins than red samples in both fresh and concentrated juices. Additionally, PRF samples showed higher solids content. As expected, in both red and purple samples, betacyanins concentration was superior to betaxanthins. Stintzing and Carle (2005) reported a similar content of betacyanins in Red prickly pear cultivar $(52.2 \mu \mathrm{g} / \mathrm{mL})$ but around half in a Purple cultivar $(151 \mu \mathrm{g} / \mathrm{mL})$.

The solids content in fresh juices, expressed in ${ }^{\circ} \mathrm{Bx}$, was higher than the reported for other red $\left(13-13.8{ }^{\circ} \mathrm{Bx}\right)$ and purple (13.3 - $15.1^{\circ} \mathrm{Bx}$ ) cultivars (Sumaya-Martínez et al., 2011), but consistent with the data reported by Stintzing, Schieber, and Carle (2001).

After adjusting to 55\% solids, the betacyanins and betaxanthins factor concentration in the red juice was 3.21 and 4.02-fold, respectively; while in the purple juice it was 3.12 and 3.31, respectively. The concentration factor of betaxanthins in both juices was higher than betacyanins factor, probably due to darkening during the thermal process; this behavior is similar to the reported by Stintzing et al. (2005) in red prickly pear juice.

Antioxidant capacity measured as DPPH percent discoloration is also shown in Table 1 for fresh and concentrated juices. RDF showed higher antioxidant capacity than PRF, although the concentration of these juices was 0.81 and $2.81 \mu \mathrm{g}$ betacyanin equivalent/mL, respectively. When juices were concentrated, DPPH percent discoloration increases. However, purple juice antioxidant capacity was again less than the red juice. The final value for DPPH discoloration is $40 \%$ for both color juices, however, and the betacyanin concentration was around four times higher in purple than in red samples ( 2.83 and $12.55 \mu \mathrm{g}$ betacyanin equivalent $/ \mathrm{mL}$, for RDC and PRC, respectively).

Table 1. Betalains content of two varieties of prickly pear juices

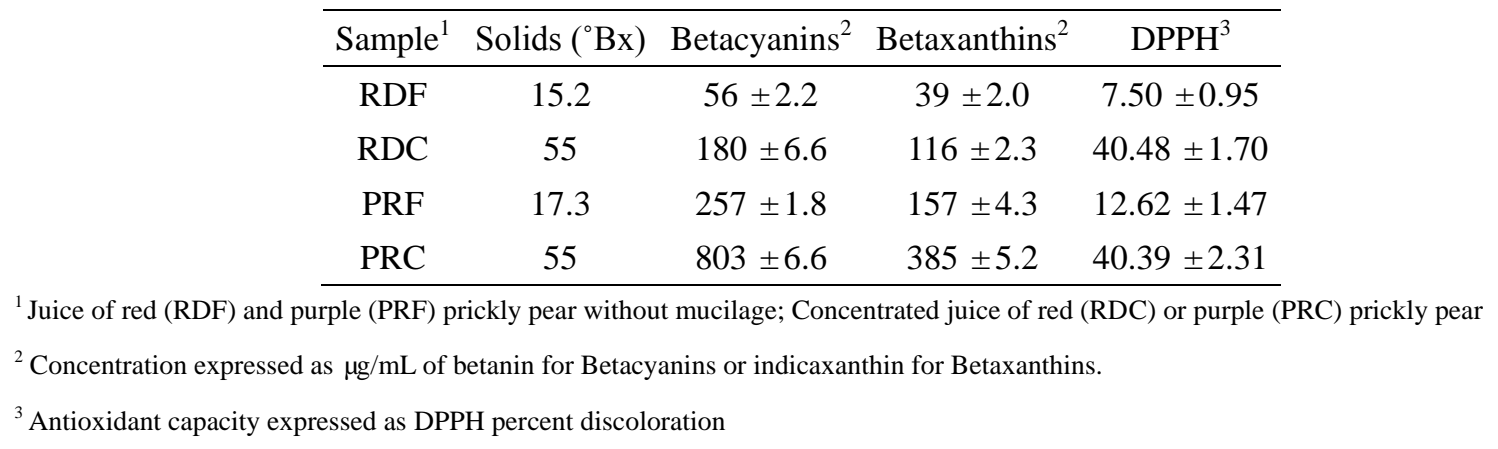

According to several authors, the antioxidant capacity of prickly pear juices may be explained by the presence of 
betalains (Butera et al., 2002; Castellar et al., 2006; Kanner, Harel, \& Granit, 2001; Stintzing et al., 2005). But according to Tesoriere, Fazzari, Allegra, and Livrea (2005) and Kuti (2004), other compounds such as biothiols, flavonols, tocopherols, flavonoids, ascorbic acid, and carotenoids may have a role in the antioxidant capacity.

The analysis of prickly pear juices (Table 2) reveals that a total of 12 betacyanins (Figure 1A) and 6 betaxanthins (Figure 1B) are present. PRC was the juice with the highest number of compounds detected, as shown in Table 2. The detected betacyanins $(\mathrm{Bc})$ and betaxanthins $(\mathrm{Bx})$ were named with consecutive numerals according to retention time. $\mathrm{Bc} 8, \mathrm{Bc} 9, \mathrm{Bc} 11, \mathrm{Bc} 12, \mathrm{Bx} 1$, and $\mathrm{Bx} 2$ were only found in $\mathrm{RDC}$ and $\mathrm{PRC}$ probably because in fresh juices their concentration was below detection limit. In the case of $\mathrm{Bc} 12, \mathrm{Bx} 1$, and $\mathrm{Bx} 2$, the betalains seem to be in the same concentration in either RDC or PRC. Bc4 and Bx3 were the most abundant in RDC followed by $\mathrm{Bc} 5, \mathrm{Bc} 1$, and $\mathrm{Bx} 4$. For PRC the order of abundance of betacyanins was $\mathrm{Bc} 5, \mathrm{Bc} 4, \mathrm{Bc} 6, \mathrm{Bc} 1$, and $\mathrm{Bc} 7$; and $\mathrm{Bx} 3$ followed by $\mathrm{Bx} 4$ and $\mathrm{Bx} 5$ for betaxanthins. The red prickly pear juices did not show $\mathrm{Bc} 2, \mathrm{Bc} 3, \mathrm{Bc} 10$, and $\mathrm{Bx} 6$ in neither fresh nor concentrated juices. Bc3 concentration did not increase during the evaporation process; it even diminishes probably due to thermosensitivity as reported for red extracts containing the betacyanin pigments which when heated, the red color gradually disappeared (Fernandez-López \& Almela, 2001). The concentration ratio of betacyanins and betaxanthins using HPLC was consistent with results obtained by spectrophotometric analysis.

Table 2. Betalains quantification by HPLC in fresh and concentrated prickly pear juices

\begin{tabular}{|c|c|c|c|c|c|c|c|c|c|}
\hline \multirow[t]{2}{*}{ Betacyanins $^{2}$} & \multicolumn{4}{|c|}{ Sample $^{1}$} & \multirow[t]{2}{*}{ Betaxanthins $^{2}$} & \multicolumn{4}{|c|}{ Sample $^{1}$} \\
\hline & $\mathrm{RDF}$ & $\mathrm{RDC}$ & PRF & PRC & & $\mathrm{RDF}$ & RDC & PRF & $\mathrm{PRC}$ \\
\hline $\mathrm{Bc} 1$ & $72.54^{\mathrm{a}}$ & $620.91^{\mathrm{d}}$ & $96.21^{\mathrm{b}}$ & $281.62^{\mathrm{c}}$ & $\mathrm{Bx} 1$ & ND & $32.50^{\mathrm{a}}$ & ND & $28.52^{\mathrm{a}}$ \\
\hline $\mathrm{Bc} 2$ & ND & ND & $290.97^{\mathrm{a}}$ & $401.49^{b}$ & $\mathrm{~B} \times 2$ & ND & $32.27^{\mathrm{a}}$ & ND & $28.95^{\mathrm{a}}$ \\
\hline $\mathrm{Bc} 3$ & ND & ND & $44.35^{\mathrm{b}}$ & $42.15^{\mathrm{a}}$ & $\mathrm{B} \times 3$ & $796.56^{\mathrm{a}}$ & $1689.52^{\mathrm{b}}$ & $3254.22^{\mathrm{c}}$ & $6834.44^{\mathrm{d}}$ \\
\hline $\mathrm{Bc} 4$ & $481.33^{\mathrm{a}}$ & $3420.67^{\mathrm{d}}$ & $711.22^{\mathrm{b}}$ & $1911.08^{\mathrm{c}}$ & $\mathrm{Bx} 4$ & $47.86^{\mathrm{a}}$ & $340.00^{\mathrm{c}}$ & $126.93^{b}$ & $762.36^{\mathrm{d}}$ \\
\hline Bc5 & $461.77^{\mathrm{a}}$ & $1185.39^{\mathrm{b}}$ & $1790.21^{\mathrm{c}}$ & $3912.18^{\mathrm{d}}$ & Bx5 & $42.34^{\mathrm{a}}$ & $42.13^{\mathrm{a}}$ & $302.91^{\mathrm{b}}$ & $519.06^{\mathrm{c}}$ \\
\hline Bc6 & $\mathrm{ND}^{4}$ & $185.24^{\mathrm{b}}$ & $86.23^{\mathrm{a}}$ & $437.44^{c}$ & Bx6 & ND & ND & ND & $33.82^{\mathrm{a}}$ \\
\hline $\mathrm{Bc} 7$ & ND & $35.24^{\mathrm{a}}$ & $166.16^{\mathrm{b}}$ & $277.21^{\mathrm{c}}$ & $\mathrm{Bx}_{\text {total }}{ }^{3}$ & 886.78 & 2136.44 & 3684.07 & 8207.19 \\
\hline $\mathrm{Bc} 8$ & ND & $37.08^{\mathrm{a}}$ & ND & $39.97^{\mathrm{b}}$ & Total betalain ${ }^{3}$ & 1902.44 & 7754.61 & 6895.59 & 15706.65 \\
\hline $\mathrm{Bc} 9$ & ND & $45.51^{\mathrm{b}}$ & $26.12^{\mathrm{a}}$ & $55.84^{\mathrm{c}}$ & & & & & \\
\hline $\mathrm{Bc} 10$ & ND & ND & ND & $55.72^{\mathrm{a}}$ & & & & & \\
\hline Bc11 & ND & $36.13^{\mathrm{b}}$ & ND & $32.46^{\mathrm{a}}$ & & & & & \\
\hline $\mathrm{Bc} 12$ & ND & $51.95^{\mathrm{a}}$ & ND & $52.24^{\mathrm{a}}$ & & & & & \\
\hline $\mathrm{Bc}$ total $^{3}$ & 1015.66 & 5618.17 & 3211.51 & 7499.46 & & & & & \\
\hline
\end{tabular}

${ }^{1}$ Juice of red (RDF) or purple (PRF) prickly pear without mucilage; Concentrated juice of red (RDC) or purple (PRC) prickly pear

${ }^{2} \mathrm{Bc}$ : Betacyanin; Bx: Betaxanthin. The number after $\mathrm{Bc}$ or $\mathrm{Bx}$ indicates the peak order in the chromatogram at 533 and $484 \mathrm{~nm}$ for betacyanins or betaxanthins respectively. Values are expressed as equivalent of $\mu \mathrm{g} / \mathrm{mL}$ of Red 40 for betacyanins or Yellow6 for betaxanthins.

${ }^{3} \mathrm{Bc}$ and $\mathrm{Bx}$ are the sum of areas for betacyanins and betaxanthins, respectively.

${ }^{\mathrm{a}-\mathrm{d}}$ Different letters in a row indicate significant differences by Tukey's HSD $(\mathrm{P}<0.05)$.

${ }^{4} \mathrm{ND}=$ Non-detected. 

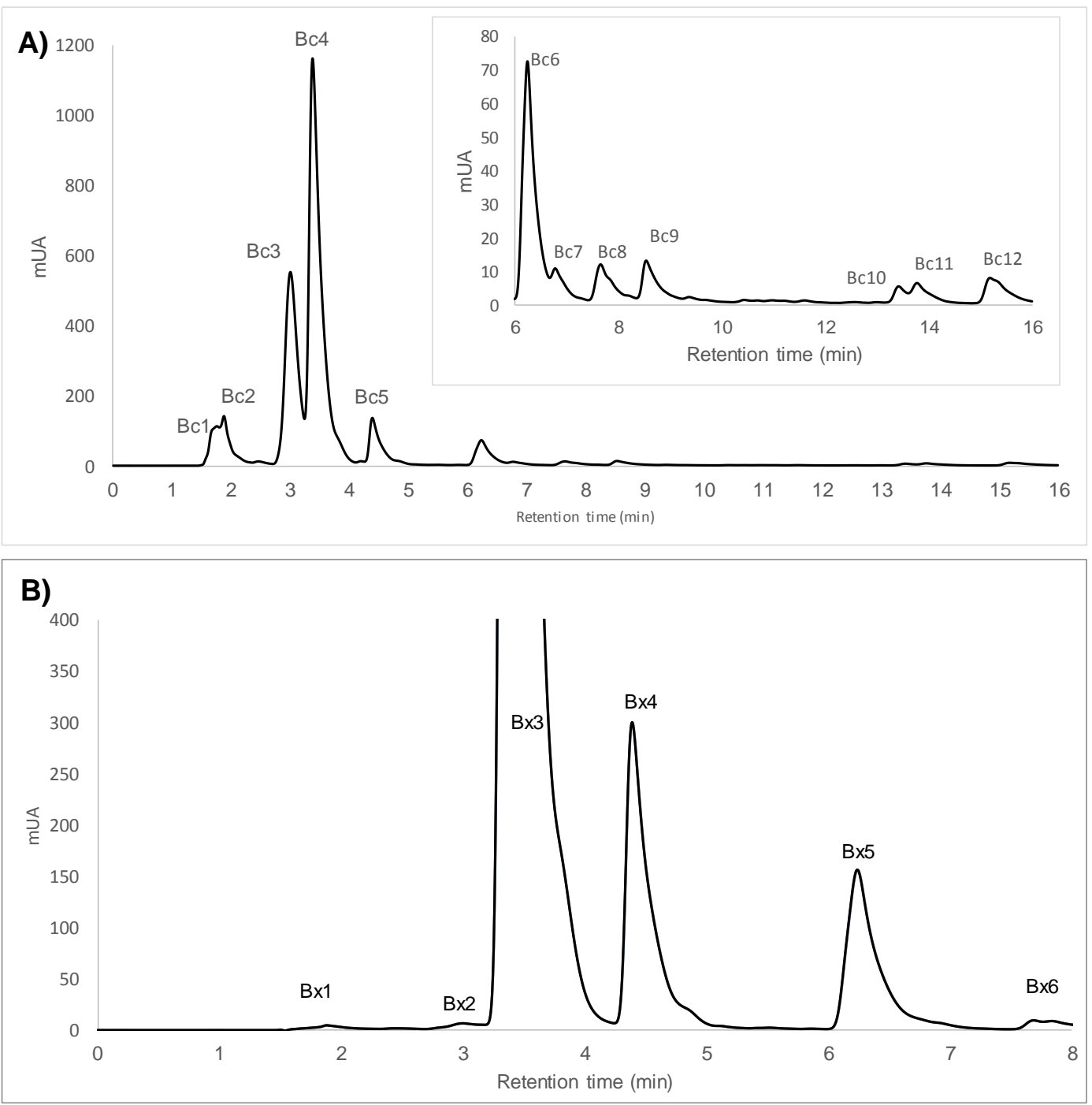

Figure 1. HPLC betalains profiles of concentrated purple prickly pear juice. A) Betacyanins at $533 \mathrm{~nm}$. B) Betaxanthins at $484 \mathrm{~nm}$

Fernandez-López and Almela (2001) state that in methanol extracts of fresh fruit of $O$. ficus-indica, only two betacyanins and one betaxanthin can be found. While Castellar et al. (2003) found in O. stricta betanin and isobetanin as the main red pigments, in $O$. undulata betanin, isobetanin, and indicaxanthin, and only betanin and indicaxanthin in O. ficus-indica. Castellanos-Santiago and Yahia (2008) reported a total of 18 betaxanthins and 6 betacyanins in 10 different cultivars of $O$. ficus-indica fruit samples, some in important amounts and some in trace amounts.

After samples underwent the microencapsulation process, only three betacyanins were detected: $\mathrm{Bc} 1, \mathrm{Bc} 4$, and $\mathrm{Bc5}$; and two betaxanthins: $\mathrm{Bx} 4$ and $\mathrm{Bx} 5$ that are typically shown in the chromatograms of the processed powders. During the microencapsulation process, Bx3 in RDC and PRC and Bc2 in PRC were either lost or transformed into other compounds probably due to the high temperature used in the process.

\subsection{Analysis of Variance (ANOVA)}

During microencapsulation matrix 0019 did not provide satisfying results for any of concentrated juices since microencapsulated powders were sticky and difficult to recover from the spray dryer. Therefore it was disregarded.

Analysis of variance (ANOVA) and Tukey's HSD (honest significant difference) test was applied separately for each of the 4 remaining data sets. Results were not the same for each concentrated juice and matrixes (Tables 3 and 4). 
RDC ANOVA results (Table 3) showed a significant effect $(\mathrm{p}<0.05)$ for most of the evaluated parameters and its interactions. Significant effects were not the same for both evaluated matrixes. For matrix 3204, powders with the lowest residual humidity and Aw were obtained at $140{ }^{\circ} \mathrm{C}$, with $2.24 \mathrm{~mL} / \mathrm{min}$ flow and $22 \%$ of the matrix. Under these conditions, the highest $\mathrm{L}^{*}$ value was obtained, meaning powders were better microencapsulated. Nevertheless, the lower flow had an undesirable effect on the betalains retention giving significant lower retention index for the 5 evaluated betalain ratios. None of the evaluated factors showed a significant effect $(\mathrm{p}<0.05)$ over DPPH scavenging capacity (Table 3$)$.

On the other hand, for matrix 4801 , powders with a significant $(\mathrm{p}<0.05)$ lower humidity and Aw were obtained at $140{ }^{\circ} \mathrm{C}, 3.36 \mathrm{~mL} / \mathrm{min}$ flow and $30 \%$ of the matrix. Nevertheless, temperature showed significant opposite effects over humidity; the highest value was obtained at $140{ }^{\circ} \mathrm{C}$. But, conditions giving powders with lower humidity had an important and negative impact on the other evaluated parameters. The most protective effect over DPPH, and color parameters $\left(\mathrm{L}^{*}, \mathrm{a}^{*}\right.$, and $\left.\mathrm{b}^{*}\right)$ were obtained at $120{ }^{\circ} \mathrm{C}$, with $2.24 \mathrm{~mL} / \mathrm{min}$ flow and $22 \%$ of the matrix. Additionally, lower temperature and flow showed a protective effect over betalains indexes (Table 3).

Table 3. Analysis of variance (ANOVA) and Tuckey's HSD test of red prickly pear concentrated juice (RDC) microencapsulation

\begin{tabular}{|c|c|c|c|c|c|c|c|c|c|c|c|c|c|c|c|c|c|c|}
\hline \multirow{3}{*}{ Variable ${ }^{\&}$} & \multicolumn{9}{|c|}{3204} & \multicolumn{9}{|c|}{4801} \\
\hline & \multirow{2}{*}{ p-value ${ }^{\#}$} & \multicolumn{2}{|c|}{ Temperature $\left({ }^{\circ} \mathrm{C}\right)$} & \multirow{2}{*}{ p-value ${ }^{\#}$} & \multicolumn{2}{|c|}{ Flow $(\mathrm{mL} / \mathrm{min})$} & \multirow{2}{*}{ p-value ${ }^{\#}$} & \multicolumn{2}{|c|}{ Matrix proportion (\%) } & \multirow{2}{*}{ p-value } & \multicolumn{2}{|c|}{ Temperature $\left({ }^{\circ} \mathrm{C}\right)$} & \multirow{2}{*}{ p-value ${ }^{\#}$} & \multicolumn{2}{|c|}{ Flow $(\mathrm{mL} / \mathrm{min})$} & \multirow{2}{*}{ p-value ${ }^{\#}$} & \multicolumn{2}{|c|}{ Matrix proportion $(\%)$} \\
\hline & & 120 & 140 & & 2.24 & 3.36 & & 22 & 30 & & 120 & 140 & & 2.24 & 3.36 & & 22 & 30 \\
\hline DPPH & 0.201 & $12.53^{\mathrm{a}}$ & $11.99^{\mathrm{a}}$ & 0.692 & $12.18^{\mathrm{a}}$ & $12.34^{\mathrm{a}}$ & 0.393 & $12.09^{\mathrm{a}}$ & $12.44^{\mathrm{a}}$ & $0.000^{* * *}$ & $16.09^{\mathrm{b}}$ & $14.57^{\mathrm{a}}$ & $0.002 * *$ & $15.36^{\mathrm{a}}$ & $15.30^{\mathrm{a}}$ & 0.861 & $15.90^{\mathrm{b}}$ & $14.76^{\mathrm{a}}$ \\
\hline Humidity & $0.000^{* * * *}$ & $4.179^{\mathrm{b}}$ & $3.621^{\mathrm{a}}$ & $0.000 * * *$ & $3.755^{\mathrm{a}}$ & $4.045^{\mathrm{b}}$ & 0.797 & $3.895^{\mathrm{a}}$ & $3.905^{\mathrm{a}}$ & $0.000^{* * *}$ & $4.021^{\mathrm{a}}$ & $4.283^{\mathrm{b}}$ & $0.000 * * *$ & $4.576^{\mathrm{b}}$ & $3.728^{\mathrm{a}}$ & $0.000^{* * * *}$ & $4.288^{\mathrm{b}}$ & $4.016^{\mathrm{a}}$ \\
\hline Aw & $0.000^{* * * *}$ & $0.255^{\mathrm{b}}$ & $0.227^{\mathrm{a}}$ & $0.007 * *$ & $0.239^{\mathrm{a}}$ & $0.244^{\mathrm{b}}$ & $0.001 * * *$ & $0.238^{\mathrm{a}}$ & $0.245^{\mathrm{b}}$ & $0.000^{* * * *}$ & $0.293^{\mathrm{b}}$ & $0.273^{\mathrm{a}}$ & $0.000^{* * * *}$ & $0.289^{\mathrm{b}}$ & $0.277^{\mathrm{a}}$ & $0.000^{* * * *}$ & $0.310^{\mathrm{b}}$ & $0.256^{\mathrm{a}}$ \\
\hline $\mathrm{L}^{*}$ & $0.010^{* *}$ & $79.66^{\mathrm{a}}$ & $80.32^{\mathrm{b}}$ & $0.000^{* * * *}$ & $79.25^{\mathrm{a}}$ & $80.73^{\mathrm{b}}$ & $0.001 * * * *$ & $80.52^{b}$ & $79.46^{\mathrm{a}}$ & $0.000^{* * *}$ & $86.23^{\mathrm{a}}$ & $87.39^{\mathrm{b}}$ & $0.000^{* * * *}$ & $86.43^{\mathrm{a}}$ & $87.18^{\mathrm{b}}$ & 0.412 & $86.85^{\mathrm{a}}$ & $86.77^{\mathrm{a}}$ \\
\hline$a^{*}$ & 0.067 & $11.10^{\mathrm{a}}$ & $11.40^{\mathrm{b}}$ & $0.000^{* * * *}$ & $11.83^{\mathrm{b}}$ & $10.66^{\mathrm{a}}$ & $0.002 * *$ & $10.91^{\mathrm{a}}$ & $11.58^{\mathrm{b}}$ & $0.018^{*}$ & $8.176^{\mathrm{b}}$ & $7.628^{\mathrm{a}}$ & 0.469 & $7.973^{\mathrm{a}}$ & $7.831^{\mathrm{a}}$ & 0.086 & $8.084^{\mathrm{a}}$ & $7.720^{\mathrm{a}}$ \\
\hline $\mathrm{b}^{*}$ & 0.828 & $10.73^{\mathrm{a}}$ & $10.77^{\mathrm{b}}$ & 0.642 & $10.79^{\mathrm{a}}$ & $10.72^{\mathrm{a}}$ & 0.060 & $10.91^{\mathrm{a}}$ & $10.59^{\mathrm{a}}$ & $0.027 *$ & $8.451^{\mathrm{b}}$ & $7.930^{\mathrm{a}}$ & 0.683 & $8.231^{\mathrm{a}}$ & $8.150^{\mathrm{a}}$ & $0.025^{*}$ & $8.454^{\mathrm{b}}$ & $7.928^{\mathrm{a}}$ \\
\hline $\mathrm{Bc} 1 \mathrm{f} / \mathrm{Bc} 1 \mathrm{i}$ & $0.001 * * *$ & $0.038^{\mathrm{a}}$ & $0.119^{\mathrm{b}}$ & $0.006^{* *}$ & $0.047^{\mathrm{a}}$ & $0.109^{\mathrm{b}}$ & $0.006^{* *}$ & $0.047^{\mathrm{a}}$ & $0.109^{\mathrm{b}}$ & $0.000^{* * * *}$ & $0.034^{\mathrm{b}}$ & $0.000^{\mathrm{a}}$ & $0.000^{* * * *}$ & $0.034^{\mathrm{b}}$ & $0.000^{\mathrm{a}}$ & $0.000^{* * * *}$ & $0.000^{\mathrm{a}}$ & $0.034^{\mathrm{b}}$ \\
\hline $\mathrm{Bc} 4 \mathrm{f} / \mathrm{Bc} 4 \mathrm{i}$ & $0.000^{* * * *}$ & $0.006^{\mathrm{a}}$ & $0.025^{\mathrm{b}}$ & $0.000^{* * * *}$ & $0.013^{\mathrm{a}}$ & $0.018^{\mathrm{b}}$ & $0.000^{* * * *}$ & $0.012^{\mathrm{a}}$ & $0.019^{b}$ & $0.000^{* * * *}$ & $0.007^{\mathrm{b}}$ & $0.005^{\mathrm{a}}$ & $0.000^{* * * *}$ & $0.007^{\mathrm{b}}$ & $0.005^{\mathrm{a}}$ & $0.000^{* * * *}$ & $0.005^{\mathrm{a}}$ & $0.007^{\mathrm{b}}$ \\
\hline Bc5f/Bc5i & $0.000^{* * * *}$ & $0.407^{\mathrm{a}}$ & $0.495^{\mathrm{b}}$ & $0.000^{* * *}$ & $0.404^{\mathrm{a}}$ & $0.498^{\mathrm{b}}$ & $0.000^{* * *}$ & $0.458^{\mathrm{b}}$ & $0.444^{\mathrm{a}}$ & $0.000^{* * * *}$ & $0.500^{\mathrm{b}}$ & $0.398^{\mathrm{a}}$ & $0.000^{* * *}$ & $0.474^{\mathrm{b}}$ & $0.424^{\mathrm{a}}$ & $0.000^{* * * *}$ & $0.419^{\mathrm{a}}$ & $0.478^{\mathrm{b}}$ \\
\hline $\mathrm{Bx} 4 \mathrm{f} / \mathrm{Bx} 4 \mathrm{i}$ & $0.000 * * *$ & $0.433^{\mathrm{a}}$ & $0.615^{\mathrm{b}}$ & $0.001 * * *$ & $0.504^{\mathrm{a}}$ & $0.543^{\mathrm{b}}$ & 0.092 & $0.517^{\mathrm{a}}$ & $0.531^{\mathrm{a}}$ & $0.000^{* * * *}$ & $0.561^{\mathrm{b}}$ & $0.447^{\mathrm{a}}$ & $0.000 * * *$ & $0.515^{\mathrm{b}}$ & $0.493^{\mathrm{a}}$ & $0.000^{* * * *}$ & $0.426^{\mathrm{a}}$ & $0.582^{\mathrm{b}}$ \\
\hline Bx5f/Bx5i & $0.000^{* * * *}$ & $0.906^{\mathrm{a}}$ & $1.493^{\mathrm{b}}$ & $0.000^{* * * * *}$ & $0.959^{\mathrm{a}}$ & $1.440^{\mathrm{b}}$ & $0.000^{* * * * *}$ & $1.916^{\mathrm{b}}$ & $0.483^{\mathrm{a}}$ & $0.000^{* * * *}$ & $0.991^{\mathrm{b}}$ & $0.000^{\mathrm{a}}$ & $0.000^{* * * *}$ & $0.991^{\mathrm{b}}$ & $0.000^{\mathrm{a}}$ & $0.000^{* * * *}$ & $0.531^{\mathrm{b}}$ & $0.459^{\mathrm{a}}$ \\
\hline
\end{tabular}

${ }^{\#}$ significant at $* \mathrm{p}<0.05, * * \mathrm{p}<0.01, * * * \mathrm{p}<0.001$

According to the results obtained, matrix 3204 showed a more protective effect than matrix 4801 in RDC juices microencapsulation over color, individual betalains, and the antioxidant capacity even if the mean DPPH value was lower in this matrix.

On the other hand, PRC ANOVA results (Table 4) showed a significant effect $(\mathrm{p}<0.05)$ for almost all the evaluated parameters and their interactions with only a few exceptions. The non-significant effects were not the same for both matrixes.

Table 4. Analysis of variance (ANOVA) and Tuckey's HSD test of purple prickly pear concentrated juice (PRC) microencapsulation

\begin{tabular}{|c|c|c|c|c|c|c|c|c|c|c|c|c|c|c|c|c|c|c|}
\hline \multirow{3}{*}{ Variable ${ }^{\&}$} & \multicolumn{9}{|c|}{3204} & \multicolumn{9}{|c|}{4801} \\
\hline & \multirow{2}{*}{$\mathrm{p}$-value ${ }^{\#}$} & \multicolumn{2}{|c|}{ Temperature $\left({ }^{\circ} \mathrm{C}\right)$} & \multirow{2}{*}{ p-value ${ }^{\#}$} & \multicolumn{2}{|c|}{ Flow (mL/min) } & \multirow{2}{*}{ p-value ${ }^{\#}$} & \multicolumn{2}{|c|}{ Matrix proportion (\%) } & \multirow{2}{*}{ p-value ${ }^{\#}$} & \multicolumn{2}{|c|}{ Temperature $\left({ }^{\circ} \mathrm{C}\right)$} & \multirow{2}{*}{ p-value ${ }^{\#}$} & \multicolumn{2}{|c|}{ Flow (mL/min) } & \multirow{2}{*}{ p-value ${ }^{\#}$} & \multicolumn{2}{|c|}{ Matrix proportion (\%) } \\
\hline & & 120 & 140 & & 2.24 & 3.36 & & 22 & 30 & & 120 & 140 & & 2.24 & 3.36 & & 22 & 30 \\
\hline DPPH & $0.000 * * *$ & $26.91^{\mathrm{b}}$ & $24.67^{\mathrm{a}}$ & 0.546 & $25.71^{\mathrm{a}}$ & $25.87^{\mathrm{a}}$ & $0.000 * * *$ & $27.24^{\mathrm{b}}$ & $24.34^{\mathrm{a}}$ & $0.043^{*}$ & $24.32^{\mathrm{b}}$ & $22.98^{\mathrm{a}}$ & $0.001 * * *$ & $22.31^{\mathrm{a}}$ & $24.98^{\mathrm{b}}$ & 0.146 & $23.20^{\mathrm{a}}$ & $24.10^{\mathrm{a}}$ \\
\hline Humidity & $0.000 * * *$ & $3.221^{\mathrm{a}}$ & $4.523^{\mathrm{b}}$ & $0.000 * * *$ & $3.380^{\mathrm{a}}$ & $4.364^{\mathrm{b}}$ & $0.000 * * *$ & $4.104^{\mathrm{b}}$ & $3.640^{\mathrm{a}}$ & $0.000^{* * *}$ & $3.671^{\mathrm{a}}$ & $4.910^{\mathrm{b}}$ & $0.000^{* * *}$ & $5.088^{\mathrm{b}}$ & $3.494^{\mathrm{a}}$ & $0.000^{* * * *}$ & $4.681^{\mathrm{b}}$ & $3.900^{\mathrm{a}}$ \\
\hline WA & $0.000^{* * * *}$ & $0.290^{\mathrm{a}}$ & $0.299^{\mathrm{b}}$ & $0.004 * *$ & $0.292^{\mathrm{a}}$ & $0.297^{\mathrm{b}}$ & $0.007 * *$ & $0.293^{\mathrm{a}}$ & $0.297^{\mathrm{b}}$ & $0.000 * * *$ & $0.335^{\mathrm{a}}$ & $0.360^{\mathrm{b}}$ & $0.000 * * *$ & $0.354^{\mathrm{b}}$ & $0.342^{\mathrm{a}}$ & $0.000 * * *$ & $0.350^{\mathrm{b}}$ & $0.345^{\mathrm{a}}$ \\
\hline $\mathrm{L}^{*}$ & $0.000^{* * * *}$ & $64.91^{\mathrm{a}}$ & $66.88^{\mathrm{b}}$ & $0.030 *$ & $66.06^{\mathrm{b}}$ & $65.74^{\mathrm{a}}$ & $0.000^{* * * *}$ & $64.28^{\mathrm{a}}$ & $67.51^{\mathrm{b}}$ & $0.000^{* * * *}$ & $77.02^{\mathrm{b}}$ & $75.99^{\mathrm{a}}$ & $0.000^{* * *}$ & $77.16^{\mathrm{b}}$ & $75.85^{\mathrm{a}}$ & $0.000 * * *$ & $77.02^{\mathrm{b}}$ & $75.99^{\mathrm{a}}$ \\
\hline$a^{*}$ & $0.007 * * *$ & $25.43^{\mathrm{a}}$ & $25.87^{\mathrm{b}}$ & $0.000 * * *$ & $26.23^{\mathrm{b}}$ & $25.07^{\mathrm{a}}$ & 0.481 & $25.61^{\mathrm{a}}$ & $25.70^{\mathrm{a}}$ & $0.000 * * *$ & $19.54^{\mathrm{a}}$ & $20.76^{\mathrm{b}}$ & $0.003 * *$ & $19.88^{\mathrm{a}}$ & $20.42^{\mathrm{b}}$ & $0.000^{* * *}$ & $19.32^{\mathrm{a}}$ & $20.98^{\mathrm{b}}$ \\
\hline$b^{*}$ & $0.000^{* * *}$ & $-4.949^{b}$ & $-5.819^{\mathrm{a}}$ & $0.003 * *$ & $-5.700^{\mathrm{a}}$ & $-5.068^{b}$ & 0.378 & $-5.315^{\mathrm{a}}$ & $-5.453^{\mathrm{a}}$ & $0.001 * * *$ & $-3.203^{b}$ & $-3.965^{\mathrm{a}}$ & $0.001 * * * *$ & $-3.164^{\mathrm{b}}$ & $-4.004^{\mathrm{a}}$ & $0.000^{* * * *}$ & $-2.288^{b}$ & $-4.880^{\mathrm{a}}$ \\
\hline $\mathrm{Bc} 1 \mathrm{f} / \mathrm{Bc} 1 \mathrm{i}$ & $0.000 * * *$ & $1.593^{\mathrm{a}}$ & $2.125^{\mathrm{b}}$ & $0.003^{* *}$ & $1.845^{\mathrm{a}}$ & $1.874^{\mathrm{b}}$ & $0.000^{* * * *}$ & $1.898^{\mathrm{b}}$ & $1.821^{\mathrm{a}}$ & $0.000 * * *$ & $1.380^{\mathrm{b}}$ & $0.898^{\mathrm{a}}$ & $0.000 * * *$ & $0.783^{\mathrm{a}}$ & $1.495^{\mathrm{b}}$ & $0.000^{* * * *}$ & $1.124^{\mathrm{a}}$ & $1.155^{\mathrm{b}}$ \\
\hline $\mathrm{Bc} 4 \mathrm{f} / \mathrm{Bc} 4 \mathrm{i}$ & $0.000^{* * * *}$ & $1.885^{\mathrm{a}}$ & $2.611^{\mathrm{b}}$ & $0.000 * * *$ & $1.947^{\mathrm{a}}$ & $2.549^{\mathrm{b}}$ & 0.256 & $2.209^{\mathrm{a}}$ & $2.287^{\mathrm{a}}$ & $0.000 * * *$ & $2.286^{\mathrm{b}}$ & $0.667^{\mathrm{a}}$ & $0.000^{* * * *}$ & $1.283^{\mathrm{a}}$ & $1.670^{\mathrm{b}}$ & $0.000^{* * * *}$ & $1.403^{\mathrm{a}}$ & $1.550^{\mathrm{b}}$ \\
\hline $\mathrm{Bc} 5 \mathrm{f} / \mathrm{Bc} 5 \mathrm{i}$ & $0.000^{* * * *}$ & $0.487^{\mathrm{b}}$ & $0.125^{\mathrm{a}}$ & $0.000 * * *$ & $0.472^{\mathrm{b}}$ & $0.140^{\mathrm{a}}$ & $0.000^{* * * *}$ & $0.244^{\mathrm{a}}$ & $0.368^{\mathrm{b}}$ & $0.000 * * *$ & $0.130^{\mathrm{a}}$ & $0.837^{\mathrm{b}}$ & $0.000 * * *$ & $0.516^{\mathrm{b}}$ & $0.451^{\mathrm{a}}$ & $0.000 * * *$ & $0.427^{\mathrm{a}}$ & $0.540^{\mathrm{b}}$ \\
\hline $\mathrm{Bx} 4 \mathrm{f} / \mathrm{Bx} 4 \mathrm{i}$ & $0.000 * * *$ & $7.278^{\mathrm{a}}$ & $8.010^{\mathrm{b}}$ & $0.000 * * *$ & $7.795^{\mathrm{b}}$ & $7.493^{\mathrm{a}}$ & $0.000^{* * * *}$ & $7.838^{\mathrm{b}}$ & $7.450^{\mathrm{a}}$ & $0.000^{* * * *}$ & $5.540^{\mathrm{b}}$ & $4.216^{\mathrm{a}}$ & $0.000^{* * * *}$ & $3.983^{\mathrm{a}}$ & $5.774^{\mathrm{b}}$ & $0.000^{* * * *}$ & $4.462^{\mathrm{a}}$ & $5.294^{\mathrm{b}}$ \\
\hline $\mathrm{Bx} 5 \mathrm{f} / \mathrm{Bx} 5 \mathrm{i}$ & $0.000^{* * * *}$ & $2.159^{\mathrm{a}}$ & $2.343^{\mathrm{b}}$ & $0.000 * * *$ & $2.454^{\mathrm{b}}$ & $2.048^{\mathrm{a}}$ & $0.000 * * *$ & $2.130^{\mathrm{a}}$ & $2.372^{\mathrm{b}}$ & $0.000 * * *$ & $1.910^{\mathrm{a}}$ & $2.857^{\mathrm{b}}$ & $0.000 * * * *$ & $2.856^{\mathrm{b}}$ & $1.911^{\mathrm{a}}$ & $0.000 * * *$ & $2.007^{\mathrm{a}}$ & $2.760^{\mathrm{b}}$ \\
\hline
\end{tabular}

${ }^{\#}$ significant at $* \mathrm{p}<0.05, * * \mathrm{p}<0.01, * * * \mathrm{p}<0.001$

Matrix 3204 gave powders with the lowest residual humidity and Aw at $120{ }^{\circ} \mathrm{C}, 2.24 \mathrm{~mL} / \mathrm{min}$ flow, and $30 \%$ matrix proportion (Table 4). Under the conditions of flow and matrix proportion significant higher values of $\mathrm{L}^{*}$, 
$a^{*}$, and $b^{*}$ were obtained as well as for the retention of most of the evaluated betalains (Table 4). However, these conditions had significant negative effects over other evaluated parameters such as DPPH scavenging capacity as well as $\mathrm{Bc} 1(\mathrm{Bc} 1 \mathrm{f} / \mathrm{Bc} 1 \mathrm{i})$, and $\mathrm{Bx} 4(\mathrm{Bx} 4 \mathrm{f} / \mathrm{Bx} 4 \mathrm{i})$ preservation.

Instead, matrix 4801 gave powders with the lower residual humidity and Aw at $120{ }^{\circ} \mathrm{C}, 3.36 \mathrm{~mL} / \mathrm{min}$ flow, and $30 \%$ matrix. (Table 4). These conditions made it possible to obtain significant higher values of DPPH as well as the higher preservation of $\mathrm{Bc} 1(\mathrm{Bc} 1 \mathrm{f} / \mathrm{Bc} 1 \mathrm{i}), \mathrm{Bc} 4(\mathrm{Bc} 4 \mathrm{f} / \mathrm{Bc} 4 \mathrm{i})$, and $\mathrm{Bx} 4(\mathrm{Bx} 4 \mathrm{f} / \mathrm{Bx} 4 \mathrm{i})$. These flow and matrix proportion gave higher $a^{*}$ and $b^{*}$ values, but the lowest $L^{*}$ values. Additionally, to obtain the lower residual humidity, significant negative effects were observed in the preservation of $\mathrm{Bc} 5(\mathrm{Bc} 5 \mathrm{f} / \mathrm{Bc5i}$ ) and $\mathrm{Bx} 5$ (Bx5f/Bx5i).

Both evaluated matrixes provide a good protective effect for PRC juices. However, matrix 3204 maintained higher DPPH values as well as better individual betalains retentions indexes.

Low values of humidity and Aw are related to long shelf life and stability of the product. A high value of $\mathrm{L}^{*}$ means that the powders are whiter because colorants are better microencapsulated and less exposed to the outside of the microcapsule. A high value of $\mathrm{a}^{*}$ means that the powders have a stronger red color, meaning that betacyanins are more easily found in the surface of the microcapsules. A higher value of $b^{*}$ means that powders have a stronger yellow color; meaning that betaxanthins are more easily found on the surface of the microcapsule.

The purple samples always showed a better antioxidant performance compared to red samples this could be due to the higher quantity of betalains present in the purple juices (Table 1). Temperature process is directly related to the extent of damage to sensitive molecules, since low flow rate causes the spraying nozzle, sprays the sample with a high air flow.

\subsection{Principal Component Analysis (PCA)}

PCA is a method that reduces data dimensionality by performing a covariance analysis between factors. In this study, the PCA was used to describe the correlation between physicochemical characteristics, antioxidant capacity, and betalain concentration with the microencapsulation parameters.

For both, RDC and PRC, PCA results were similar. For RDC, the two first principal components described $92.84 \%$ of the total variance (Figure 2). PCA factorial map of scores (Figure 2A) shows the separation of two well-defined groups mostly by PC1. Matrix 3204 samples formed a compact group located on the negative side of the graphic while matrix 4801 formed a more dispersed group on the positive side.

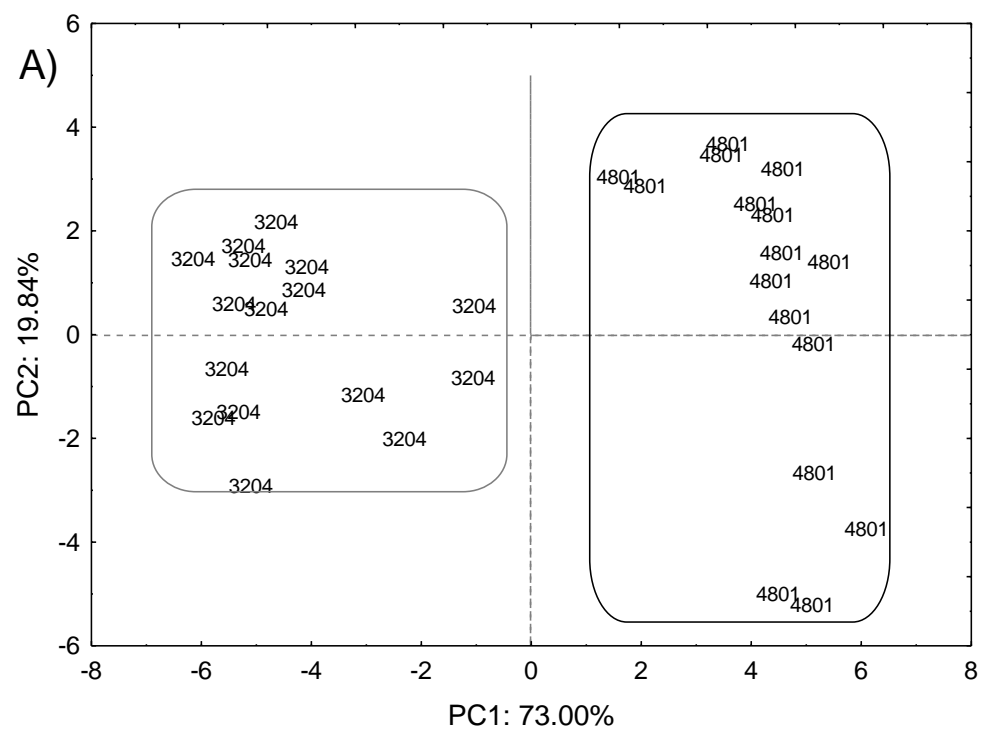




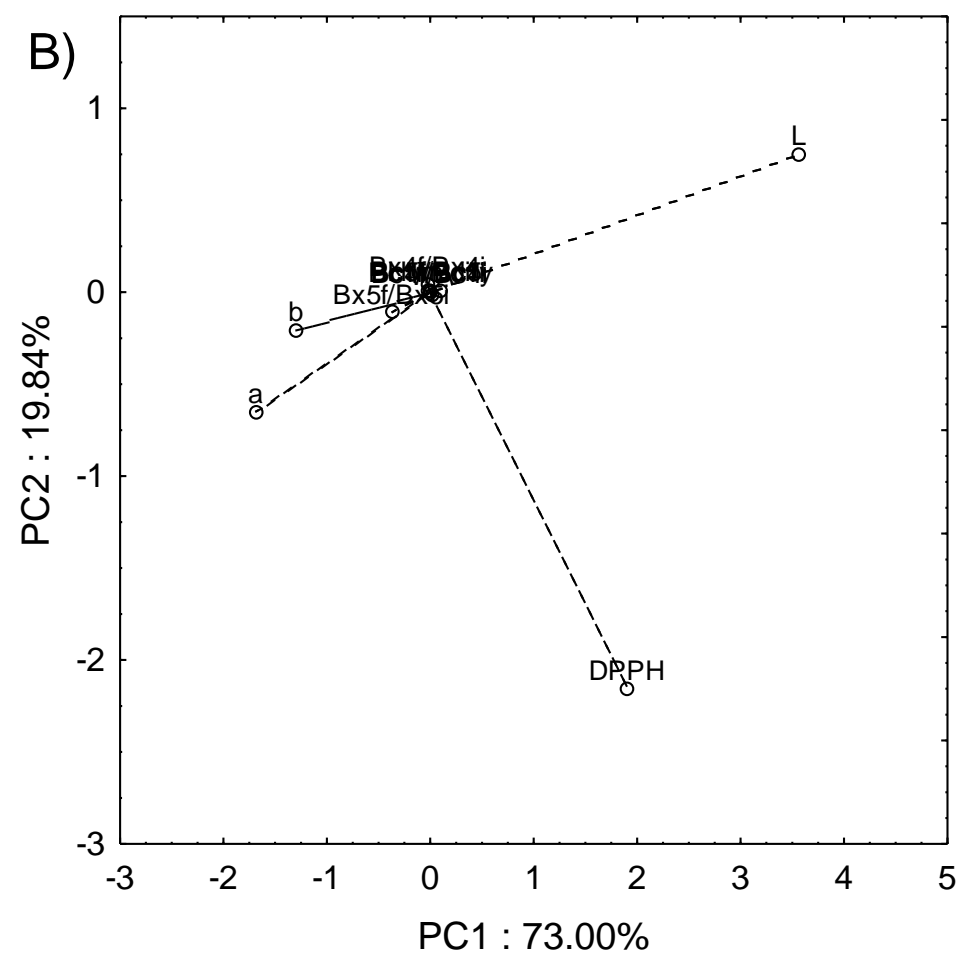

Figure 2. Red prickly pear microencapsulated powders of concentrated juices (RDC) principal component analysis (PCA) plots of the first two principal components (PC1 and PC2). A) Factorial map; and B) factor loadings plot. Samples code is the matrix code

As shown in factor loadings plot (Figure 2B), PC1 was inversely correlated with $\mathrm{a}^{*}$ and $\mathrm{b}^{*}$; and directly correlated with DPPH antioxidant capacity and $\mathrm{L}^{*}$. On the other hand, PC2 was directly correlated to $\mathrm{L}^{*}$ and inversely correlated to a DPPH, a* and b* (Figure 2B). These observations suggested that matrix 3204 showed a more protective effect over color but less protective effect over DPPH antioxidant capacity. Nevertheless, the samples could not be separated according to temperature, flow or matrix proportion; they seem to have less effect when matrix 3204 is used than for matrix 4801. The other evaluated parameters did not show strong correlations with the principal components. Samples could not be separated according to the other spray-drying evaluated factors.

For PRC, PCA factorial map described $89.65 \%$ of total variance (Figure 3). PCA factorial map of scores (Figure 3A) shows two well-separated groups mostly by PC1. Matrix 3204 samples formed a compact group on the negative side of PC1. Matrix 4801 samples formed a more dispersed group defined by a combination of PC1 and PC2 (Figure 3A).

The factor loadings plot (Figure 3B) shows $\mathrm{PC} 1$ has a strong positive correlation with $\mathrm{L}^{*}$ and important positive correlation with $\mathrm{b}^{*}$ and negative correlation with $\mathrm{a}^{*}$ and DPPH. Instead, PC2 show a strong positive correlation with DPPH antioxidant and negative with $\mathrm{a}^{*}$ suggesting that matrix 3204 showed a more protective effect over the color and DPPH antioxidant capacity. Matrix 4801 seems to have a more protective effect over color parameter $b^{*}$ and samples where better microencapsulated (higher $L^{*}$ ) but it shows a huge variability demonstrated by samples dispersion in the factorial map (Figure 3A). These results suggest that temperature, flow, and matrix concentration have more impact on the evaluated parameters when matrix 4801 is used than for matrix 3204, even if samples could not be grouped according to those parameters. 

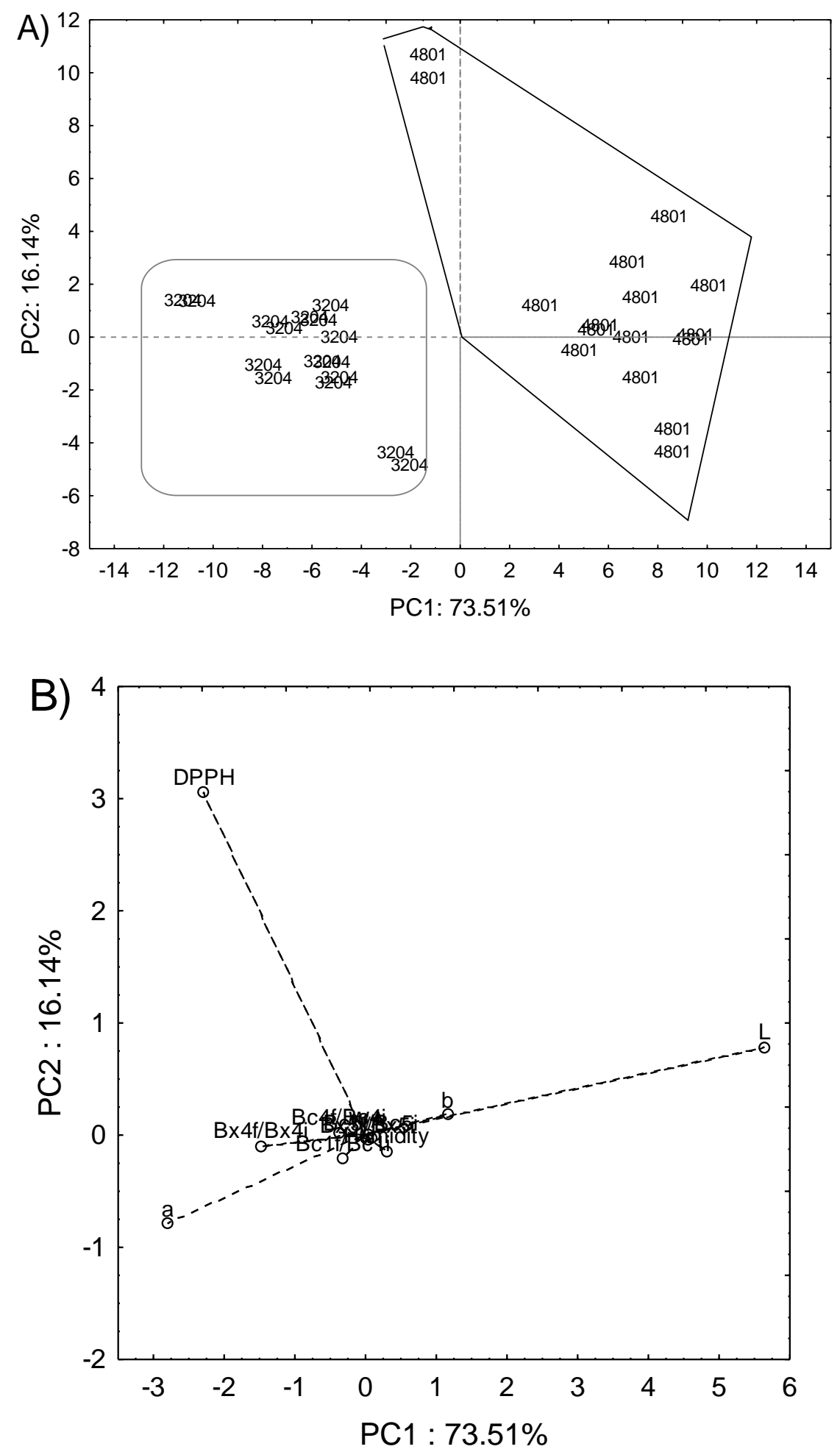

Figure 3. Purple prickly pear microencapsulated powders of concentrated juices (PRC) principal component analysis (PCA) plots of the first two principal components (PC1 and PC2). A) Factorial map; and B) factor loadings plot. Samples code is the matrix code 


\section{Conclusions}

This work revealed that spray drying microencapsulation is a viable option for preserving betalains present in prickly pear juice and their antioxidant capacity. Evaluated matrixes showed different effects according to the prickly pear color evaluated due to the different betalain content and profile. The matrix 3204 gave the best protective effect for both color juices. Spray drying conditions should be chosen according to the raw material, and the further use of the obtained powders. Further studies will be needed to evaluate stability and shelf life of final powders.

\section{Acknowledgment}

The first author, Alberto Castañeda Yáñez gratefully acknowledges Consejo Nacional de Ciencia y Tecnología (CONACYT) for granting scholarship 332104.

\section{References}

Burda, S., \& Oleszek, W. (2001). Antioxidant and Antiradical Activities of Flavonoids. Journal of Agricultural and Food Chemistry, 49(6), 2774-2779. https://doi.org/10.1021/jf001413m

Butera, D., Tesoriere, L., Di Gaudio, F., Bongiorno, A., Allegra, M., Pintaudi, A. M., ... Livrea, M. A. (2002). Antioxidant activities of Sicilian prickly pear (Opuntia ficus indica) fruit extracts and reducing properties of its betalains: betanin and indicaxanthin. Journal of Agricultural and Food Chemistry, 50(23), 6895-6901. https://doi.org/10.1021/jf025696p

Castellanos-Santiago, E., \& Yahia, E. M. (2008). Identification and quantification of betalains from the fruits of 10 Mexican prickly pear cultivars by high-performance liquid chromatography and electrospray ionization mass spectrometry. Journal of Agricultural and Food Chemistry, 56(14), 5758-5764. https://doi.org/10.1021/jf800362t

Castellar, M. R., Obón, J. M., \& Fernández-López, J. A. (2006). The isolation and properties of a concentrated red-purple betacyanin food colourant from Opuntia stricta fruits. Journal of the Science of Food and Agriculture, 86(1), 122-128. https://doi.org/10.1002/jsfa.2285

Castellar, R., Obón, J. M., Alacid, M., \& Fernández-López, J. A. (2003). Color properties and stability of betacyanins from Opuntia fruits. Journal of Agricultural and Food Chemistry, 51(9), 2772-2776. https://doi.org/10.1021/jf021045h

Chattopadhyay, P., Chatterjee, S., \& Sen, S. K. (2008). Biotechnological potential of natural food grade biocolorants. African Journal of Biotechnology, 7(17), 2972-2985.

Díaz Sánchez, F., Santos López, E. M., Filardo Kerstupp, S., Villagómez Ibarra, R., \& Scheinvar, L. (2006). Colorant extraction from red prickly pear (Opuntia lasiacantha) for food application. Electronic Journal of Environmental, Agricultural and Food Chemistry, 5(2), 1330-1337.

Fernandez-López, J. A., \& Almela, L. (2001). Application of high-performance liquid chromatography to the characterization of the betalain pigments in prickly pear fruits. Journal of Chromatography A, 913(1-2), 415-420. https://doi.org/10.1016/S0021-9673(00)01224-3

Fukumoto, L. R., \& Mazza, G. (2000). Assessing antioxidant and prooxidant activities of phenolic compounds. Journal of Agricultural and Food Chemistry, 48(8), 3597-3604. https://doi.org/10.1021/jf000220w

Kanner, J., Harel, S., \& Granit, R. (2001). Betalains--a new class of dietary cationized antioxidants. Journal of Agricultural and Food Chemistry, 49(11), 5178-5185. https://doi.org/10.1021/jf010456f

Kuti, J. O. (2004). Antioxidant compounds from four Opuntia cactus pear fruit varieties. Food chemistry, 85(4), 527-533. https://doi.org/10.1016/S0308-8146(03)00184-5

Parra Huertas, R. A. (2010). Revisión: Microencapsulación de Alimentos. Revista Facultad Nacional de Agronomía, 63(2), 5669-5684. https://doi.org/10.15446/rfnam

Pimienta-Barrios, E., Zanudo, J., Yepez, E., Pimienta-Barrios, E., \& Nobel, P. S. (2000). Seasonal variation of net $\mathrm{CO}_{2}$ uptake for cactus pear (Opuntia ficus-indica) and pitayo (Stenocereus queretaroensis) in a semi-arid environment. Journal of arid environments, 44(1), 73-83.

Reyes-Agüero, J. A., Aguirre-Rivera, J. R., \& Hernández, H. M. (2005). Systematic notes and a detailed description of Opuntia ficus-indica (1.) Mill. (Cactaceae). Agrociencia, 39, 395-408.

Stintzing, F. C., \& Carle, R. (2005). Cactus stems (Opuntia spp.): A review on their chemistry, technology, and uses. Molecular Nutrition \& Food Research, 49(2), 175-194. https://doi.org/10.1002/mnfr.200400071 
Stintzing, F. C., Herbach, K. M., Mosshammer, M. R., Carle, R., Yi, W., Sellappan, S., ... Felker, P. (2005). Color, betalain pattern, and antioxidant properties of cactus pear (Opuntia spp.) clones. Journal of Agricultural and Food Chemistry, 53(2), 442-451. https://doi.org/10.1021/jf048751y

Stintzing, F. C., Schieber, A., \& Carle, R. (2001). Phytochemical and nutritional significance of cactus pear. European Food Research and Technology, 212(4), 396-407. https://doi.org/10.1007/s002170000219

Sumaya-Martínez, M. T., Cruz-Jaime, S., Madrigal-Santillán, E., García-Paredes, J. D., Cariño-Cortés, R., Cruz-Cansino, N., ... Alanís-García, E. (2011). Betalain, acid ascorbic, phenolic contents and antioxidant properties of purple, red, yellow and white cactus pears. International journal of molecular sciences, 12(10), 6452-6468. https://doi.org/10.3390/ijms12106452

Tesoriere, L., Fazzari, M., Allegra, M., \& Livrea, M. A. (2005). Biothiols, taurine, and lipid-soluble antioxidants in the edible pulp of Sicilian cactus pear (Opuntia ficus-indica) fruits and changes of bioactive juice components upon industrial processing. Journal of Agricultural and Food Chemistry, 53(20), 7851-7855. https://doi.org/10.1021/jf050636f

Yañez, J., Salazar, J., Chaires, L., Jiménez, J., Márquez, M., \& Ramos, E. (2002). Aplicaciones biotecnológicas de la microencapsulación. Avance y perspectiva, 21, 313-319.

\section{Copyrights}

Copyright for this article is retained by the author(s), with first publication rights granted to the journal.

This is an open-access article distributed under the terms and conditions of the Creative Commons Attribution license (http://creativecommons.org/licenses/by/4.0/). 